\title{
DETALHE E CÁLCULO DE LIGAÇÕES METÁLICAS EM FLUXO DE TRABALHO BIM: CASO DE ESTUDO DE UM AEROPORTO
}

\author{
António Carvalheira ${ }^{(1)}$, Patrício Rocha ${ }^{(2)}$, José Carlos Lino ${ }^{(1)}$ \\ (1) NEWTON - Consultores de Engenharia, Lda., Porto, jclino@newton.pt; \\ https://orcid.org/0000-0002-1227-600X \\ (2) proMetheus, Instituto Politécnico de Viana do Castelo, Viana do Castelo, Portugal, \\ procha@estg.ipvc.pt, https://orcid.org/0000-0002-6811-0797
}

\begin{abstract}
Resumo
Apesar da utilização de metodologias BIM no contexto da construção metálica já estar implementada há vários anos em Portugal, a sua integração num fluxo de trabalho contínuo, desde a compatibilização com o modelo de Arquitetura, passando pelo cálculo estrutural das ligações até ao envio para o fabricante, é ainda pouco frequente. No presente artigo pretendese dar testemunho da experiência obtida num caso de estudo das ligações metálicas para uma expansão num aeroporto. A obra em questão envolve novos terminais, construídos predominantemente em estrutura porticadas, com coexistência de vários tipos de perfis metálicos, nomeadamente perfis reconstituídos soldados e perfis laminados a quente (tubulares e não tubulares).

O fluxo de trabalho realizado na NEWTON, enquanto projetista das ligações metálicas, baseouse na recepção do modelo BIM da Arquitetura (em formato RVT), do modelo BIM de Estruturas (em formato Tekla) e das listas de esforços enviadas pela equipa projetista geral. O trabalho desenvolvido incluiu essencialmente a definição das geometrias de ligações metálicas possíveis a partir das condicionantes impostas pelo processo de compatibilização Arquitetura-Estrutura bem como das condicionantes de transporte. As ligações estudadas envolveram vários casos de complexidade relevante, incorporando frequentemente nós com interseção de mais de cinco perfis. O cálculo das ligações foi efetuado através de software dedicado (IDEA Statica), com base em interoperabilidade com o modelo BIM de Estruturas (Tekla). Posteriormente ao cálculo, foi efetuada exportação em modelo tridimensional sob formato de interoperabilidade proprietário (baseado em navegador web). O artigo inclui exemplos de aplicação deste fluxo de trabalho, discutindo vantagens e dificuldades.
\end{abstract}

\section{Introdução}

A NEWTON - Consultores de Engenharia, Lda. tem sido pioneira na implementação de metodologias e processos BIM, enquanto projetista de estruturas, praticamente desde o aparecimento deste novo conceito. Com o surgimento de novos e variados projectos, cada vez 
mais exigentes no que diz respeito à implementação BIM, a NEWTON tem procurado destacarse de forma a corresponder aos padrões de qualidade a que tem habituado os seus clientes e parceiros. Concomitantemente, isso implica investimento em formação, tempo e em novos softwares [1].

O presente artigo pretende dar a conhecer um projeto de ligações metálicas de um aeroporto desenvolvido pela NEWTON e o fluxo de trabalho adotado para dar resposta ao pretendido. $\mathrm{O}$ envolvimento de ferramentas BIM neste fluxo de trabalho torna-se imprescindível num projeto desta grandeza em que a compatibilização de especialidades (em particular, Arquitetura Estruturas) tem um papel fundamental na escolha da geometria e tipo de ligações a adotar. Além disso, torna possível a análise rigorosa de nós de grande complexidade geométrica permitindo que, a jusante, se evitem/antecipem problemas ao nível do detalhe e do fabrico.

Entende-se que este é um testemunho importante para a comunidade científica e, em particular para a comunidade PTBIM, por ser um testemunho sobre um assunto menos abordado, num contexto muito particular.

Pretende-se, portanto, tirar ilações, vantagens e desvantagens, da utilização do BIM na metodologia de trabalho adotada, com o intuito de, no futuro, se poderem otimizar e melhorar processos, bem como perceber quais as melhores abordagens a seguir em projectos semelhantes.

\section{Caso de Estudo de um Aeroporto}

\subsection{Descrição Geral}

A NEWTON foi consultada por parceiros nacionais para estar envolvida na realização de um projeto de ligações metálicas de uma expansão de um aeroporto europeu.

Esta expansão tem um desenvolvimento total de cerca de $390 \mathrm{~m}$ e consiste na criação de um novo edifício com vários terminais sobre os quais incidiu o projeto de ligações metálicas e, consequentemente, o alvo de estudo que resultou no presente artigo. A estrutura dos terminais é composta por uma estrutura metálica predominantemente porticada com coexistência de vários tipos de perfis, nomeadamente perfis reconstituídos soldados e perfis laminados a quente (tubulares e não tubulares) (Ver Figura 1).

O papel da NEWTON passou por rececionar toda a informação já existente do projeto de estruturas e das outras especialidades, processá-la, filtrá-la, e calcular as ligações metálicas contemplando todas as condicionantes associadas. No final, coube a outra empresa parceira preparar toda a modelação do projeto de estruturas (incluindo ligações) em ambiente BIM (Tekla), para se poder avançar para o fabrico da estrutura dos terminais. Cientes do papel específico a desempenhar, sabendo da importância e necessidade da utilização do BIM no presente projeto, adotou-se um fluxo de trabalho devidamente enquadrado que será explicado mais à frente neste artigo. 

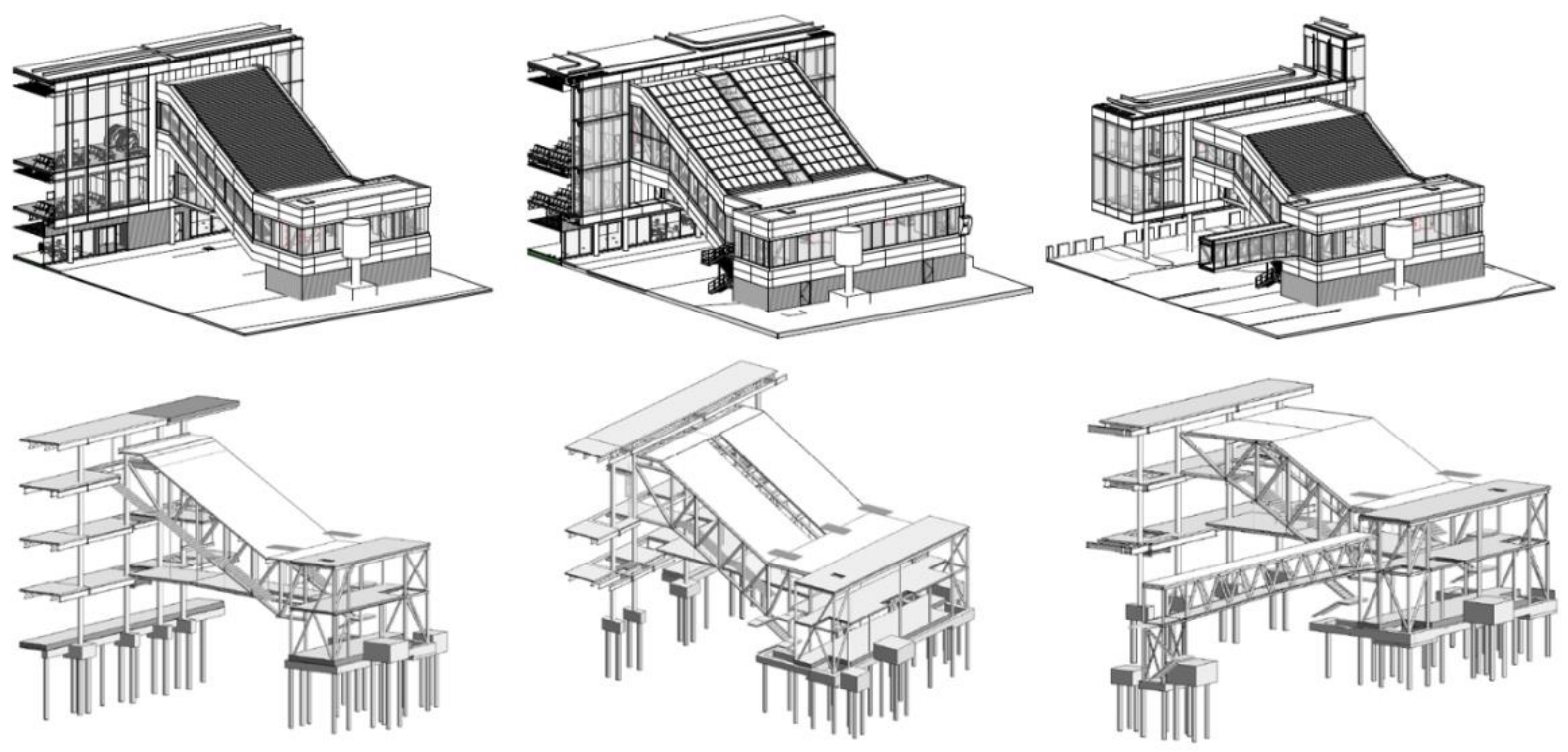

Figura 1: Conjunto de estruturas dos vários terminais do aeroporto (Arquitetura e Estruturas).

\subsection{Meio Envolvente e Condicionantes do Projeto}

Todos os projectos, por norma, têm condicionantes e adversidades muito próprias que os marcam e caracterizam. Tratando-se este de uma expansão de um aeroporto, pela sua complexidade e importância, foi também fortemente influenciado por várias condicionantes.

Primeiramente, o projeto global envolveu várias entidades e equipas com diferentes objetivos e responsabilidades. O alinhamento e cooperação entre todos os envolvidos foi fundamental para a superação das dificuldades que iam surgindo mas, nem sempre se deu de um modo eficiente e próspero, causando entropias, atrasos e, por vezes, repetição de trabalhos.

Complementarmente, como o funcionamento das instalações do aeroporto não podia ser posto em causa nem prejudicado (dada a sua importância óbvia), surgiram imensas condicionantes ao nível dos métodos construtivos e de montagem a adotar. Toda esta problemática teve de ser prevista e contemplada em projeto tendo influência direta sobre a conceção do projeto das ligações que determina como será feito o encaixe e montagem dos vários elementos constituintes da estrutura.

Ainda se podem acrescentar as próprias limitações associadas ao meio de transporte disponível (camiões), tanto no que diz respeito ao peso e às dimensões máximas dos elementos a transportar, bem como, quanto à necessidade de compatibilização entre as diversas especialidades (em particular a Arquitetura), que no seu conjunto constituíram desafios não negligenciáveis no desenvolvimento do projeto de ligações metálicas.

Por fim, pelo facto da base de trabalho sobre as quais se elaborou o projeto de ligações metálicas, ser a base usada no projeto de concurso da construção e não de um projeto de execução com cotagens, geometrias e detalhes devidamente fornecidos, originou dificuldades no arranque do trabalho, no alinhamento entre todos os envolvidos, agravando as condicionantes anteriormente referidas. 


\section{Fluxo de trabalho adotado em ambiente BIM}

Para dar resposta ao desafio proposto foi necessário adotar metodologias de trabalho que contemplassem todas as condicionantes anteriormente referidas e permitissem $\mathrm{o}$ desenvolvimento do projeto o mais eficazmente possível, dentro dos prazos estipulados.

Pretendeu-se também implementar o BIM no projeto das ligações metálicas, conseguindo assim dar continuidade à utilização desta ferramenta (igualmente utilizada pelos restantes envolvidos) e, desta forma, tirar proveito das suas vantagens na interpretação das soluções e integração no projeto global.

Assim sendo, apresenta-se um fluxograma (ver Figura 2) do trabalho desenvolvido no âmbito do presente projeto.
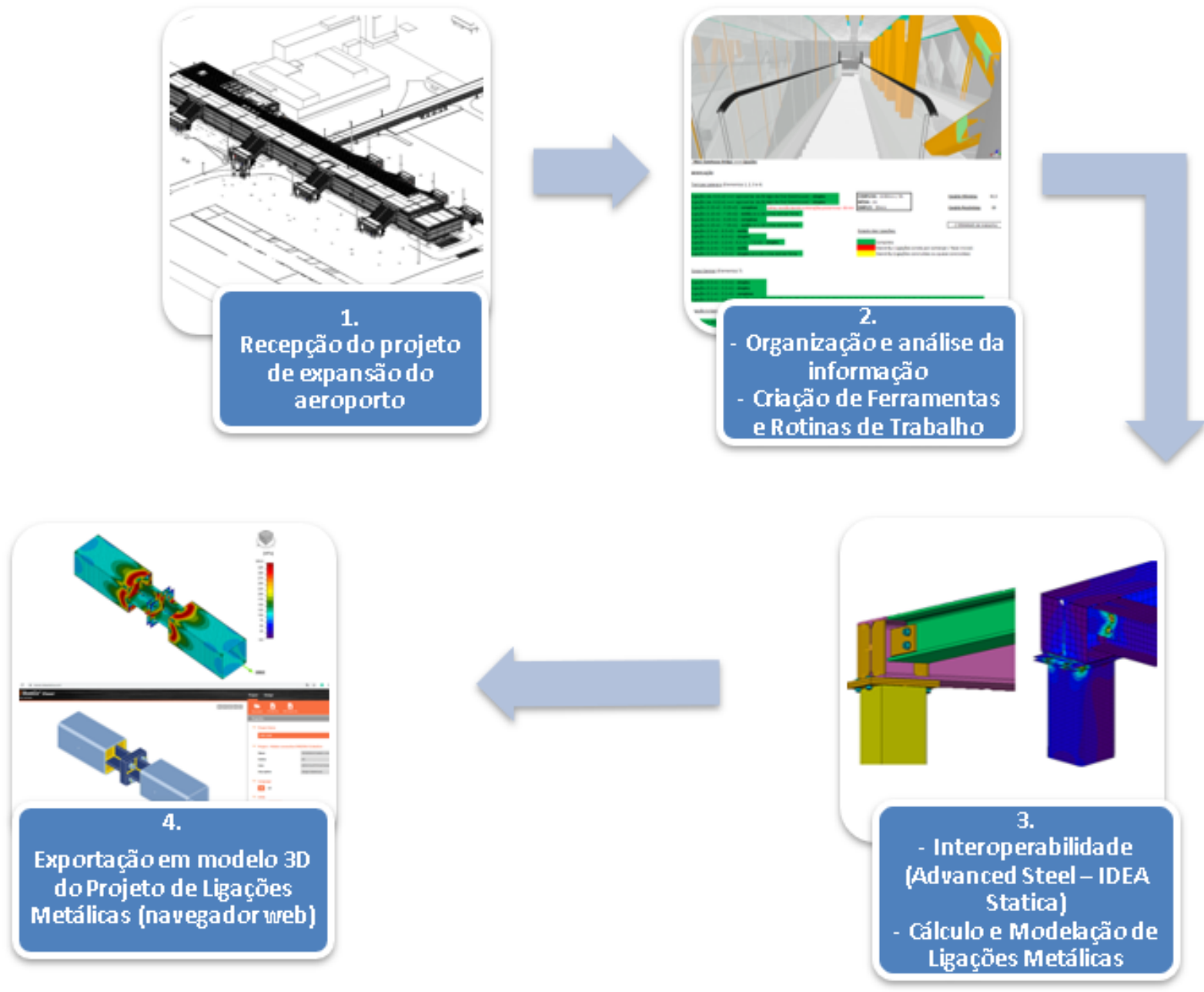

\section{FLUXO DE TRABALHO EM AMBIENTE BIM}

Figura 2: Fluxograma do trabalho desenvolvido.

De seguida, lista-se detalhadamente o fluxo de trabalho apresentado na Figura 2. 
1. Receção do projeto de expansão do aeroporto em formato digital, incluindo o projeto de Arquitetura (em formato RVT), o projeto de estruturas (projeto de concurso) (em formato Tekla), a listagem de todos os esforços e cálculos associados ao projeto de estruturas (estritamente necessários para o projeto das ligações metálicas), bem como outras informações de menor relevância para o presente trabalho;

2. Organização e análise de toda a informação recebida (descrita no ponto anterior) de forma a criarem-se ferramentas e rotinas de trabalho úteis para o desenvolvimento do projeto, passando por:

- Criação de uma estratégia que permitisse identificar todos os nós das várias estruturas dos terminais sem originar repetições ou casos confusos (foi adotada uma nomenclatura específica para o caso);

- Interpretação dos esforços e cálculos enviados pela equipa projetista geral e criação de folhas de cálculo (em formato Excel) que permitissem identificar rapidamente os esforços num determinado nó;

- Desenvolvimento de folhas organizativas e metodologias de gestão que possibilitassem o controlo e o progresso do trabalho (importante, tendo em conta a grande quantidade e variedade de ligações metálicas necessárias);

- Estudo dos projetos de estruturas e arquitetura exportando ambos os modelos BIM para o formato IFC, permitindo assim a utilização de ferramentas de Clash Detection que tornaram evidentes as várias incompatibilidades entre as especialidades referidas;

- Formalização de dúvidas e levantamento de incompatibilidades, na sequência de todo o trabalho descrito nos pontos anteriores.

3. Exportação do projeto de estruturas para o software Advanced Steel (por ser o usado habitualmente para estruturas em aço pela equipa alocada a este projeto que não teria tanta proficiência se fosse direto do Tekla), a partir do qual foi feita a sincronização com o software dedicado IDEA Statica, que permitiu a modelação e cálculo das ligações metálicas (a interoperabilidade entre os dois softwares tornou possível a modelação e cálculo de qualquer tipologia de nós com o máximo rigor e detalhe);

4. Por fim, após concluído o cálculo das ligações no software IDEA Statica, foi efetuada exportação em modelo tridimensional sob formato de interoperabilidade proprietário (baseado em navegador web), para que a empresa responsável pelo fabrico das estruturas metálicas pudesse avançar com a preparação das mesmas (contemplando as ligações) e, posteriormente, iniciar a fabricação.

A utilização de ferramentas BIM esteve bem patente nas várias fases do projeto de ligações metálicas e foi fulcral no desenvolvimento do mesmo, permitindo não só detetar problemas e incompatibilidades em fases preliminares como também calcular as ligações / nós de forma otimizada e rigorosa. A interoperabilidade em todo o processo foi bem patente com usos de diferentes formatos de informação e provenientes de diversos autores mas que no final decorreu sem problemas assinaláveis. Seguidamente, na Figura 3, exemplifica-se a aplicação destas ferramentas para um caso concreto. 

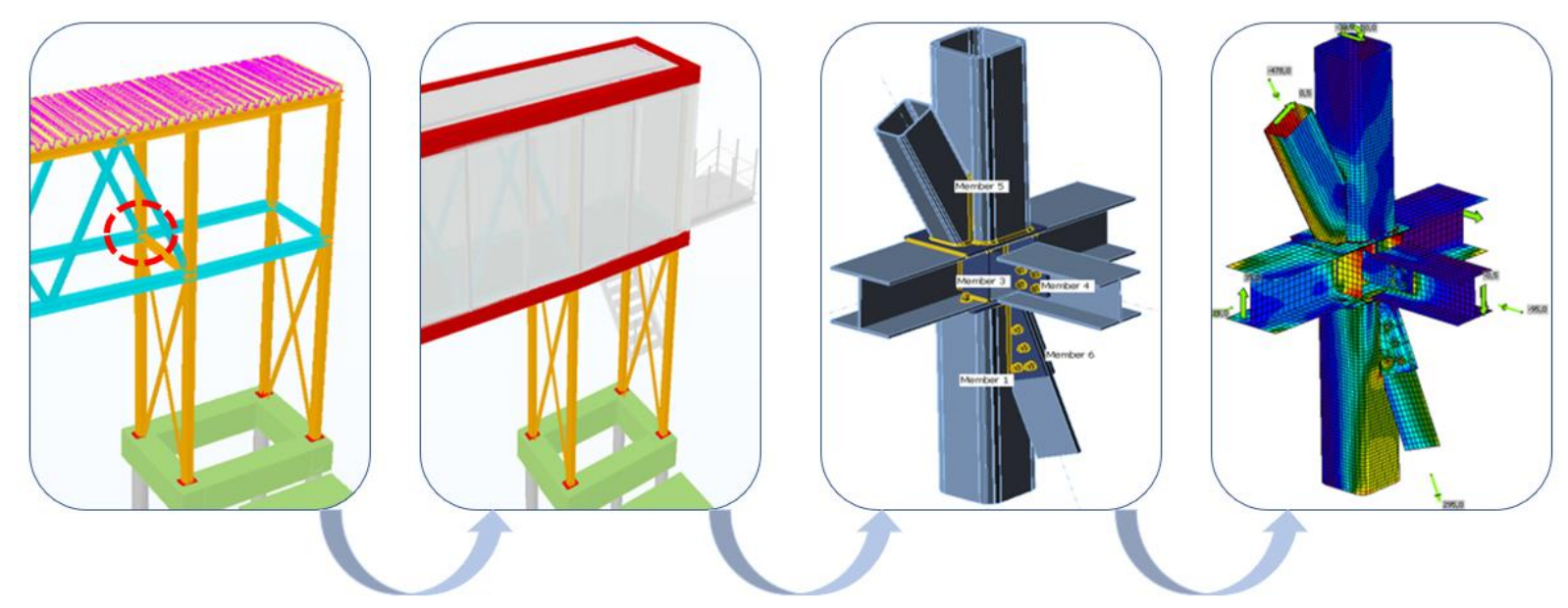

Figura 3: Aplicação da metodologia BIM a um nó específico.

Relativamente à análise e dimensionamento das ligações metálicas, conforme já referido, recorreu-se ao software IDEA Statica. Este, apresenta uma enorme versatilidade permitindo a interoperabilidade com diversos softwares de modelação (como é o caso do Advanced Steel, Revit ou do Tekla) tornando possível o cálculo de nós com variadas e complexas geometrias [2]. Em termos de cálculo, mais concretamente, o software IDEA Statica apresenta um método singular, designado de CBFEM - Component - Based Finite Element Model, que resulta da combinação de dois métodos usados para analisar e dimensionar ligações metálicas: o Método das Componentes (preconizado no Eurocódigo 3 [3]) e o Método dos Elementos Finitos [4].

Assim, foi possível analisar e dimensionar todos os elementos que compõem uma ligação (chapas, perfis, cutelos, soldaduras, parafusos, aberturas, entre outros) que incluiu a possibilidade de concretizar, com rigor, diversos tipos de possibilidades como análises de tensão / deformação, análises de rigidez ou análises de encurvadura. Todas estas ferramentas foram cruciais para uma melhor perceção do comportamento do nó e determinantes na escolha da melhor solução para a ligação.

Seguidamente, nas Figuras 4 e 5, apresentam-se alguns exemplos de ligações e de análises efetuadas.
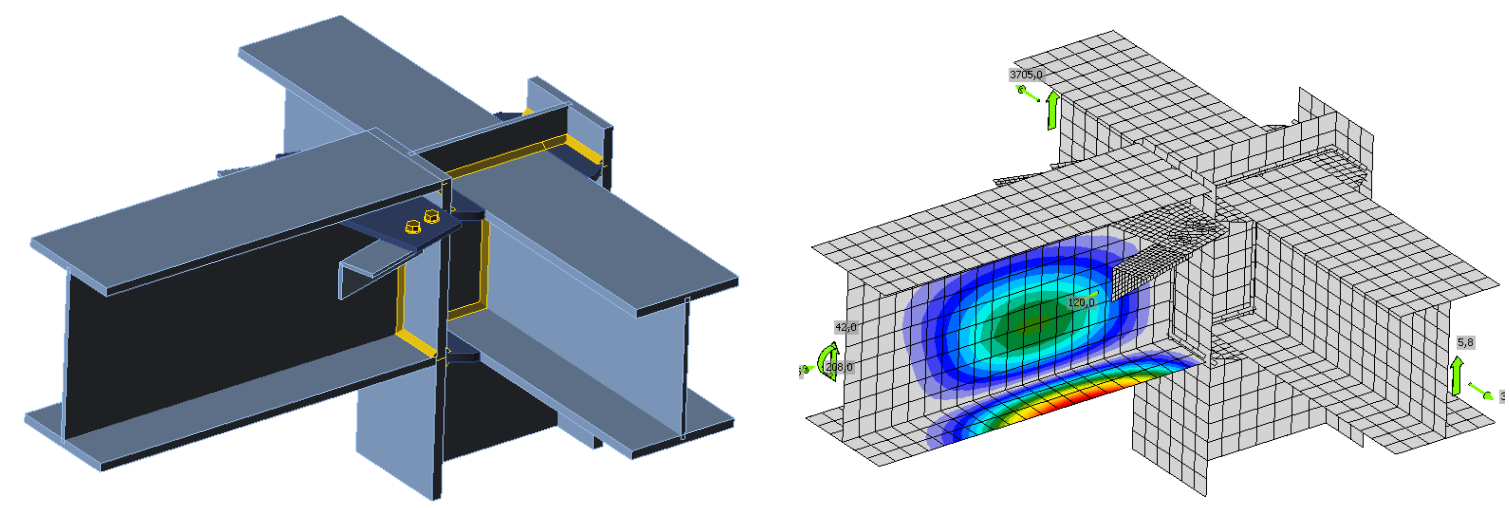

Figura 4: Exemplo da análise de um nó no software IDEA Statica: à esquerda - modelação da ligação; à direita - análise da encurvadura. 

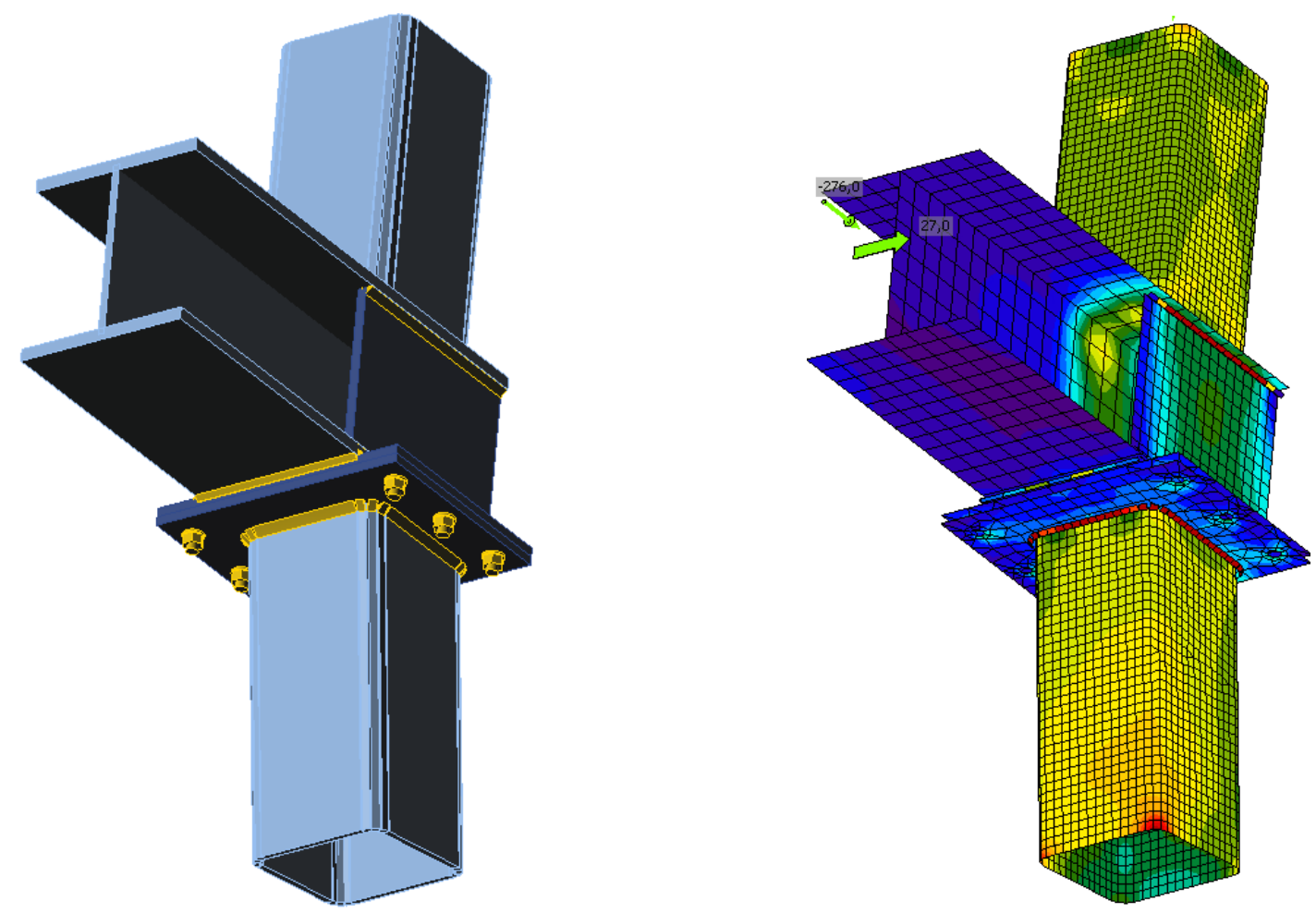

Figura 5: Exemplo da análise de um nó no software IDEA Statica: à esquerda - modelação da ligação; à direita - análise de tensões.

\section{Conclusões}

Comprova-se, mais uma vez, a importância da utilização de metodologias de trabalho baseadas em ambiente BIM no processo diário de uma empresa, pois permitem não só responder às necessidades que os atuais projetos exigem, quer ao nível do rigor geométrico, de detalhe, entre outros requisitos, mas também melhorar os respetivos workflows [5].

O fluxo de trabalho utilizado no presente projeto permitiu, de uma forma bastante satisfatória, dar resposta ao desafio e concluir o processo de uma forma mais expedita. Deixa-se apenas uma nota de que, relativamente ao software IDEA Statica: porque apenas permite uma interoperabilidade unidirecional com o software Advanced Steel, ou outro idêntico. Não sendo possível realizar o processo iterativo característico do cálculo e otimização associado ao dimensionamento das ligações metálicas (esse passo terá de ser feito de forma manual) o processo origina algum trabalho repetitivo que consume tempo e recursos eventualmente otimizáveis.

É claro que todos estes aspetos não excluem que se continue a investir no planeamento inicial, interpretando os dados do problema e antecipando possíveis dificuldades. Por esse motivo, a fim de evitar que as mesmas possam ter um impacto significativo no fluxo de trabalho, recomenda-se, a título de exemplo, a adoção de técnicas e processos de gestão de trabalho e de informação por todos os envolvidos no projeto desde as fases iniciais de conceção até às fases de detalhe e preparação. 
O futuro passa por combinar este tipo de técnicas e conceitos com metodologias BIM originando fluxos de trabalho mais capazes que possam aumentar a produtividade, a qualidade e o processo colaborativo entre todos os envolvidos [6].

\section{Agradecimentos}

Cumpre aqui deixar um agradecimento especial à empresa CONSTRUSOFT nas pessoas dos seus sócios Nuno Pires e Vakis Kokorellis, sem os quais este trabalho não teria sido possível. A CONSTRUSOFT não só possibilitou a aplicação e teste do software IDEA Statica com o qual foram calculadas as ligações, como apoiou tecnicamente este trabalho durante todo o projeto, mostrando-se permanentemente disponível para o esclarecimento de dúvidas. Acresce que a vasta experiência dos seus representantes, na área da preparação e fabricação metálica, permitiu o diálogo permanente para a adoção das melhores práticas.

\section{Referências}

[1] C. Gomes, J. C. Lino e R. P. Santos, "Guia de Implementação da Metodologia BIM", $1^{\circ}$ Congresso Português de Building Information Modelling - Guimarães, 2016.

[2] https://www.construsoft.com/bim-software/idea-statica - Porto, 2020.

[3] Comité Europeu de Normalização, Eurocódigo 3: Projeto de estruturas de aço. Parte 1-8: Dimensionamento de ligações.

[4] L. Šabatka, F. Wald, J. Kabeláč, D. Kolaja e M. Pospíšil, "Structural Analysis and Design of Steel Connections Using Component-Based Finite Element Model", Journal of Civil Engineering and Architecture 9 - 2015.

[5] J. Soares, H. Marques, J. Oliveira e A. Araújo, "New Bugesera International Airport Aplicação Prática", $2^{\circ}$ Congresso Português de Building Information Modelling - Lisboa, 2018.

[6] B. Ferreira, J. Lima, J. Rio e J. P. Martins, "Integração da Tecnologia BIM no Projeto de Estruturas de Betão", Encontro Nacional Betão Estrutural - Porto, 2012 